\title{
PENGEMBANGAN BAHAN AJAR ELEKTRONIK (BAE) BERBANTUAN FLIPBOOK BERBASIS KETERAMPILAN PEMECAHAN MASALAH DENGAN PENDEKATAN CTL PADA PEMBELAJARAN MATEMATIKA KELAS V SEKOLAH DASAR
}

\author{
Rusnilawati $^{1)}$, Eva Gustiana ${ }^{2)}$ \\ ${ }^{1}$ PGSD, FKIP, Universitas Muhammadiyah Surakarta Jawa Tengah; ${ }^{2}$ PGPAUD, STKIP Muhammadiyah \\ Kuningan Jawa Barat \\ email: ${ }^{1}$ rus874@ums.ac.id; ${ }^{2}$ evagustiana84@yahoo.com
}

\begin{abstract}
The aim of this research is to produce Flipbook-based Electronic Teaching Materials based on problem solving skills with CTL Approach in Elementary School Class V that was valid, practical, and effective. The type of research is development research. This research developed Flipbookassisted Electronic Teaching Materials on the mathematics learning of Class V Elementary School by using the 4-D, the model was developed by Thiagarajan, Semmel, and Semmel. The validation result indicated that The Electronic Teaching Materials developed was feasible to be used with good minimum category. The results of the field trial showed that The Electronic Teaching Material developed was practical and effective. The practicality was assessed by the students and reached 62.5 with good category. The practicality assessed by the teacher reached 25.5 (very good) on material aspect; 13.5 (very good) on the language aspect; and 35 (very good) on aspects of interest and influence. The student's problem solving skill on posttest is $92.9 \%$. There was an increase in scores obtained by the students in steps that were understanding the problem, planning, implementing the plan, and looking back. The percentage of student attitudes toward mathematics with very good category increased $42,8 \%$, the percentage of student attitudes toward mathematics with good category increased $31,25 \%$.
\end{abstract}

Keywords: electronics, teaching, materials, mathematics, class $v$

\section{PENDAHULUAN}

Guru perlu menggunakan bahan ajar yang menarik agar dapat memotivasi siswa dalam belajar matematika. Peraturan Pemerintah Nomor 19 Tahun 2005 Pasal 19 ayat 1 tentang Standar Nasional Pendidikan menjelaskan bahwa proses pembelajaran harus dilaksanakan secara interaktif, inspiratif, menyenangkan, menantang, dan memotivasi peserta didik (PP No. 19 Tahun 2005: 17). Oleh karena itu dalam pembelajaran matematika agar siswa tidak merasa jenuh atau takut, maka guru perlu menggunakan bahan ajar yang menarik dan dapat memotivasi siswa. Menurut Hosnan (2014: 209) pembelajaran aktif (active learning) adalah kegiatan belajar dengan menggunakan seluruh potensi yang dimiliki peserta didik secara optimal, dengan tujuan agar mereka dapat mencapai hasil belajar yang memuaskan sesuai dengan karakteristik kepribadian yang dimiliki oleh siswa. Hal tersebut sesuai dengan Peraturan Pemerintah Nomor 58 Tahun 2013 tentang proses pembelajaran yang mengubah pola pembelajaran pasif menjadi pembelajaran aktif-mencari dimana siswa aktif membangun pengetahuannya yang diperkuat dengan model pembelajaran pendekatan saintifik (Mendikbud, 2014: 2).

Saat ini perkembangan teknologi di dunia sudah semakin maju, begitu juga perkembangan IT dalam dunia pendidikan. 
Menurut Surjono (2010) teknologi pembelajaran yang dewasa ini aplikasinya berupa pemanfaatan proses dan produk teknologi informasi dan komunikasi (information and communication technology/ICT) untuk memecahkan masalah-masalah pendidikan dan pembelajaran, memiliki banyak manfaat atau keuntungan. Salah satu teknologi yang dapat digunakan dalam kegiatan pembelajaran adalah Flipbook. Program ini biasa digunakan untuk mendesain buku elektronik. Selain itu, program ini juga bisa menampilkan video, gambar, animasi, tulisan, dan lain sebagainya. Program ini juga bisa dibuka pada HP android. Dengan menggunakan Flipbook guru dapat menampilkan bahan ajar yang akan disampaikan dalam bentuk yang lebih menarik..

Namun di Sekolah Dasar program Flipbook masih jarang digunakan. Hal tersebut dikarenakan para guru masih awam dalam penggunaan IT khususnya pada pembelajaran matematika. Berdasarkan hasil penelitian yang dilakukan oleh Anwariningsih (2014) mengenai kesiapan penggunaan ICT pada Sekolah Dasar menunjukkan bahwa 70\% guru-guru kelas belum memiliki kemampuan dalam mengoperasikan komputer. Sedangkan $30 \%$ guru sudah mampu mengoperasikan komputer akan tetapi hanya sebatas untuk mengetik saja/keperluan administrasi sekolah. Selain iti, penilaian siswa dalam pembelajaran matematika sering berfokus pada hasil belajar kognitif saja. Seperti yang dijelaskan Guan, et al (2011: 257) bahwa "student assessment in the mathematics classroom often focuses on cognitive learning outcomes".

Program Flipbook dapat digunakan untuk mendesain Bahan Ajar Elektronik (BAE) sebagai sebuah inovasi dalam bentuk multimedia pembelajaran. Munir (2013: 51) menjelaskan

bahwa

multimedia mempercayakan pada model pembelajaran Contextual Teaching and Learning (CTL) yang berpusat pada berbagai aspek yang mendukung pembelajaran, lingkungan belajar, kelas, laboratorium, komputer, websites, maupun worksite. Sesuai dengan pendapat tersebut Mayer (2009: 4) menjelaskan bahwa multimedia merujuk pada teknologi untuk menyajikan materi dalam bentuk verbal dan visual.

Berdasarkan hasil pra-penelitian yang diperoleh dan didukung dengan pendapat para pakar yang sudah dijelaskan sebelumnya, maka penting untuk mengembangkan Bahan Ajar Elektronik (BAE) berbantuan Flipbook Berbasis Keterampilan Pemecahan Masalah dengan Pendekatan CTL pada pembelajaran Matematika Kelas V Sekolah Dasar. Permasalahan yang diteliti yaitu bagaimana mengembangkan perangkat pembelajaran yang valid, praktis, dan efektif.

\section{METODE PENELITIAN}

Penelitian ini bertujuan menghasilkan suatu produk yaitu Bahan Ajar Elektronik (BAE) Berbantuan Flipbook Berbasis Keterampilan Pemecahan Masalah dengan Pendekatan Contextual Teaching and Learning (CTL) pada Pembelajaran Matematika Kelas V Sekolah Dasar. Penelitian ini dirancang dengan menggunakan model pendekatan penelitian dan pengembangan. Penelitian ini menggunakan model pengembangan yang dikemukakan oleh Thiagarajan, Dorothy S. Semmel, dan Melvyn I. Semmel yang dikenal dengan model pengembangan 4D. Model pengembangan tersebut terdiri dari empat tahap yaitu tahap mendefinisikan (define), tahap merancang (design), tahap mengembangkan (develop), dan tahap 
mendesiminasikan

(Thiagarajan, et.al, 1974: 5).

Pengembangan produk dilakukan mulai bulan Januari 2017. Validasi Bahan Ajar Elektronik dilaksanakan pada bulan Mei 2017. Uji coba terbatas dilaksanakan pada bulan Juli. Uji coba lapangan dilaksanakan pada bulan Agustus dan September 2017. Uji coba bahan ajar elektronik yang dikembangkan sudah dilaksanakan di Kelas V SD Negeri 17 Kuningan. Desiminasi produk dilaksanakan pada bulan Desember 2017.

\section{Subjek Penelitian}

Subjek uji coba terbatas adalah kelas V yang terdiri dari 18 siswa dengan kategori kemampuan matematika cukup, baik, dan sangat baik. Kelas V terdiri dari 5 (lima) kelas. Selanjutnya dipilih secara acak 1 (satu) kelas sebagai kelas uji coba lapangan yaitu Kelas VB (35 siswa).

\section{Prosedur}

Prosedur pengembangan penelitian terdiri dari empat tahap yaitu tahap mendefinisikan (define), tahap merancang (design), tahap mengembangkan (develop), dan tahap mendesiminasikan (disseminate) (Hobri, 2010: 16).

Tahap pendefinisian dilaksanakan sebelum mengembangkan bahan ajar dengan menentukan tujuan dan permasalahan sebagai patokan dalam penyusunan Bahan Ajar Elektronik. Tahap pendefinisian terdiri dari lima langkah yaitu analisis awal-akhir, analisis siswa, analisis konsep, analisis tugas, dan spesifikasi tujuan pembelajaran. Tahap merancang (design) bertujuan untuk menyusun Bahan Ajar Elektronik (BAE) berbantuan Flipbook berbasis keterampilan pemecahan masalah dengan Pendekatan CTL pada pembelajaran matematika Kelas V
Sekolah Dasar, sehingga diperoleh prototipe (contoh Bahan Ajar Elektronik) dalam upaya meningkatkan hasil belajar meliputi: kemampuan pemecahan masalah dan sikap terhadap matematika. Tahap perancangan terdiri dari empat langkah yaitu penyusunan tes, pemilihan media, pemilihan format, dan perancangan awal (desain awal). Tahap mengembangkan (develop) bertujuan untuk menghasilkan draf Bahan Ajar Elektronik (BAE) berbantuan Flipbook yang telah direvisi berdasarkan masukan para ahli dan data yang diperoleh dari uji coba. Kegiatan pada tahap ini adalah penilaian para ahli, uji coba terbatas, dan uji coba lapangan. Tahap desiminasi (disseminate) merupakan tahap penggunaan Bahan Ajar Elektronik (BAE) berbantuan Flipbook yang telah dikembangkan pada skala yang lebih luas, misalnya di kelas lain, sekolah lain, oleh guru lain.

\section{Instrumen dan Teknik Pengumpulan Data}

Kelayakan Bahan Ajar Elektronik (BAE) berbantuan Flipbook yang telah dikembangkan dinilai dengan mengukur kevalidan bahan ajar, kepraktisan, dan keefektifan penggunaannya di kelas. Instrumen pengumpulan data yang digunakan meliputi: lembar validasi bahan ajar, angket respon siswa, angket penilaian guru, tes kemampuan pemecahan masalah, dan angket sikap terhadap matematika.

\section{Teknik Analisis Data}

Data yang berupa komentar, saran, revisi, dan hasil observasi dianalisis secara deskriptif kualitatif. Data tersebut digunakan sebagai masukan untuk merevisi produk yang dikembangkan. Data yang diperoleh melalui lembar validasi bahan ajar elektronik, angket 
respon siswa, angket penilaian guru, tes kemampuan pemecahan masalah, dan angket sikap siswa terhadap matematika dianalisis secara statistika deskripsitf.

Data yang berupa rating dengan skala 5 dikonversikan menajdi data kualitatif yang juga berskala 5. Kriteria konversi data tersebut dilakukan berdasarkan kriteria yang disajikan dalam Tabel 1 (Widoyoko, 2009: 238).

Tabel 1. Kriteria Konversi Data Kuantitatif ke Data Kualitatif

\begin{tabular}{ccc}
\hline Nilai & Interval Skor & Kategori \\
\hline $\mathrm{A}$ & $X>\bar{X}_{i}+1,8 s b_{i}$ & Sangat Baik \\
$\mathrm{B}$ & $\bar{X}_{i}+0,6 s b_{i}<X \leq \bar{X}_{i}+1,8 s b_{i}$ & Baik \\
$\mathrm{C}$ & $\bar{X}_{i}-0,6 s b_{i}<X \leq \bar{X}_{i}+0,6 s b_{i}$ & Cukup \\
$\mathrm{D}$ & $\bar{X}_{i}-1,8 s b_{i}<X \leq \bar{X}_{i}-0,6 s b_{i}$ & Kurang \\
$\mathrm{E}$ & $X \leq \bar{X}_{i}-1,8 s b_{i}$ & Sangat Kurang \\
\hline
\end{tabular}

Keterangan:

$\bar{X}_{i}=$ rerata skor ideal $=\frac{1}{2}($ skor maksimum + skor minimum $)$

$s b_{i}=$ simpangan baku ideal $=\frac{1}{6}($ skor maksimum - skor minimum $)$

$X=$ skor aktual

Adapun tabel penilaian skala Likert untuk analisis kevalidan bahan ajar elektronik disajikan pada Tabel 2. Sedangkan analisis data kepraktisan diperoleh dari angket respon siswa dan penilaian guru disajikan pada Tabel 3 dan Tabel 4. Keefektifan bahan ajar elektronik dinilai berdasarkan angket sikap terhadap matematika. Data tersebut berdasar pada kategori yang terdiri atas 5 pilihan respon. Tabel penilaian skala Likert untuk sikap terhadap matematika disajikan pada Tabel 5. Selain itu, keefektifan bahan ajar elektronik juga dinilai berdasar pada tes kemampuan pemecahan masalah. Tahap pemecahan masalah yang dinilai yaitu kemampuan memahami masalah, menyusun rencana, melaksanakan rencana, dan mengoreksi jawaban.

Tabel 2. Kevalidan Bahan Ajar

\begin{tabular}{ccc}
\multicolumn{3}{c}{ Aspek Isi } \\
\hline Nilai & Interval Skor & Kategori \\
\hline A & $X>33,6$ & Sangat Baik \\
B & $27,2<X \leq 33,6$ & Baik \\
C & $20,8<X \leq 27,2$ & Cukup \\
D & $14,4<X \leq 20,8$ & Kurang \\
E & $X \leq 14,4$ & Sangat Kurang \\
\hline
\end{tabular}

\begin{tabular}{ccc}
\multicolumn{3}{c}{ Aspek Bahasa } \\
\hline Nilai & Interval Skor & Kategori \\
\hline A & $X>8,4$ & Sangat Baik \\
B & $6,8<X \leq 8,4$ & Baik \\
C & $5,2<X \leq 6,8$ & Cukup \\
D & $3,6<X \leq 5,2$ & Kurang \\
E & $X \leq 3,6$ & Sangat Kurang \\
\hline
\end{tabular}

\begin{tabular}{ccc}
\multicolumn{3}{c}{ Aspek Tampilan } \\
\hline Nilai & Interval Skor & Kategori \\
\hline A & $X>16,8$ & Sangat Baik \\
B & $13,6<X \leq 16,8$ & Baik \\
C & $10,4<X \leq 13,6$ & Cukup \\
D & $7,2<X \leq 10,4$ & Kurang \\
E & $X \leq 7,2$ & Sangat Kurang \\
\hline
\end{tabular}

\begin{tabular}{ccc}
\multicolumn{2}{c}{ Dampak Penggunaan } \\
\hline Nilai & Interval Skor & Kategori \\
\hline A & $X>8,4$ & Sangat Baik \\
B & $6,8<X \leq 8,4$ & Baik \\
C & $5,2<X \leq 6,8$ & Cukup \\
D & $3,6<X \leq 5,2$ & Kurang \\
E & $X \leq 3,6$ & Sangat Kurang \\
\hline
\end{tabular}


Tabel 3. Angket Respon Siswa

\begin{tabular}{ccc}
\hline Nilai & Interval Skor & Kategori \\
\hline A & $X>63$ & Sangat Baik \\
B & $51<X \leq 63$ & Baik \\
C & $39<X \leq 51$ & Cukup \\
D & $27<X \leq 39$ & Kurang \\
E & $X \leq 27$ & Sangat Kurang \\
\hline
\end{tabular}

Tabel 4. Kriteria Penialian Sikap Siswa Terhadap

Matematika

\begin{tabular}{ccc}
\hline Nilai & Interval Skor & Kategori \\
\hline A & $X>134,4$ & Sangat Baik \\
B & $108,8<X \leq 134,4$ & Baik \\
C & $83,2<X \leq 108,8$ & Cukup \\
D & $57,6<X \leq 83,2$ & Kurang \\
E & $X \leq 57,6$ & Sangat Kurang \\
\hline
\end{tabular}

Tabel 5. Angket Penilaian Guru

\begin{tabular}{|c|c|c|c|c|}
\hline \multirow[b]{2}{*}{ Nilai } & \multicolumn{3}{|c|}{ Interval Skor } & \multirow[b]{2}{*}{ Kategori } \\
\hline & Materi & Bahasa & $\begin{array}{l}\text { Ketertarikan dan } \\
\text { pengaruh }\end{array}$ & \\
\hline $\mathrm{A}$ & $X>25,2$ & $X>12,6$ & $X>33,54$ & Sangat Baik \\
\hline $\mathrm{B}$ & $20,4<X \leq 25,2$ & $10,2<X \leq 12,6$ & $27.18<X \leq 33,54$ & Baik \\
\hline $\mathrm{C}$ & $15,6<X \leq 20,4$ & $7,8<X \leq 10,2$ & $20,82<X \leq 27,18$ & Cukup \\
\hline $\mathrm{D}$ & $10,8<X \leq 15,6$ & $5,4<X \leq 7,8$ & $14,46<X \leq 20,82$ & Kurang \\
\hline $\mathrm{E}$ & $X \leq 10,8$ & $X \leq 5,4$ & $X \leq 14,46$ & Sangat Kurang \\
\hline
\end{tabular}

Bahan ajar elektronik yang dikembangkan dikatakan valid, jika minimal tingkat validitas yang dicapai adalah kategori baik. Bahan ajar elektronik dikatakan praktis berdasarkan angket respon siswa dan penilaian guru jika minimal kategori yang dicapai adalah baik. Selain itu keefektifan dari bahan ajar elektronik yang dikembangkan ditinjau dari dua aspek yaitu kemampuan pemecahan masalah dan sikap terhadap matematika. Bahan ajar elektronik dikatakan efektif jika: a) terdapat peningkatan kemampuan pemecahan masalah berdasarkan hasil pretest dan posttest; b) persentase jumlah siswa pada tes kemampuan pemecahan masalah yang memenuhi KKM adalah $\geq 80 \%$; c) terdapat peningkatan jumlah siswa yang memiliki sikap positif terhadap matematika.

\section{HASIL DAN PEMBAHASAN}

Produk yang dikembangkan dalam penelitian ini adalah Bahan Ajar Elektronik (BAE) berbantuan Flipbook berbasis keterampilan pemecahan masalah dengan pendekatan Contextual Teaching and Learning (CTL) pada pembelajaran matematika kelas V Sekolah Dasar. Aspek kualitas produk pengembangan berdasarkan kualitas produk Nieveen (1999: 127) yang terdiri dari 3 aspek, yaitu valid, praktis, dan efektif. Materi yang diujicobakan pada uji coba lapangan adalah volume bangun ruang serta jaring-jaring bangun ruang.

\section{Hasil Pengembangan Produk Awal}

Pada tahap pendefinisian akan dideskripsikan lima tahap kegiatan yang dilakukan yaitu analisis awal-akhir, analisis siswa, analisis konsep, analisis tugas, dan spesifikasi tujuan pembelajaran. Analisis awal-akhir adalah studi tentang permasalahan yang dihadapi guru dalam pembelajaran matematika di SD kelas V. Analisis tersebut dilaksanakan pada saat pra-penelitian melalui kegiatan observasi pembelajaran, wawancara guru, dan pemberian angket pada siswa. Prapenelitian dilaksanakan di Kelas VA SD Negeri 17 Kuningan pada bulan Februari 2017. Pada analisis awal-akhir ditemui beberapa permasalahan dalam pembelajaran matematika di kelas V SD. Berdasarkan hasil observasi, bahan ajar yang digunakan guru masih dalam bentuk buku ajar cetak dan LKS sehingga masih belum menggunakan bahan 
ajar berbasis multimedia khususnya Flipbook. Penilaian guru masih cenderung pada kognitif dan jarang menggunakan soal-soal pemecahan masalah. Selain itu, nilai prestasi belajar siswa juga masih rendah $(55 \%$ siswa belum mencapai nilai ketuntasan belajar).

Analisis karakteristik peserta didik dilaksanakan sebagai tahap awal dalam pengembangan perangkat pembelajaran. Penelitian pengembangan ini diujicobakan pada siswa SD Kelas V. Pemilihan materi yang dirancang dalam perangkat pembelajaran perlu disesuaikan dengan karakteristik siswa SD Kelas V. Berdasarkan kajian teori anak usia Sekolah Dasar berada pada tahap operasional konkret. Hal tersebut harus dipertimbangkan dalam pembelajaran, bahwa belajar akan bermakna jika materi pelajaran sesuai dengan minat dan bakat peserta didik. Karakteristik yang dilihat oleh peneliti adalah bahwa anak SD menyukai gambar berwarna, kalimat yang digunakan tidak terlalu rumit, permasalahan yang disajikan hendaknya sesuai dengan permasalahan yang dialami sehari-hari oleh siswa. Adanya ilustrasi gambar akan lebih mempermudah siswa dalam belajar.

Setelah melakukan analisis karakteristik peserta didik, peneliti melakukan analisis konsep yaitu meninjau materi yang dikembangkan dan menyusun materi apa saja yang akan dimasukkan dalam Bahan Ajar Elektronik. Materi matematika yang dikembangkan yaitu bangun ruang dan pecahan. Teori bruner menjelaskan bahwa peroses belajar matematika terdiri dari tahap enaktif, ikonik, dan simbolik. Sesuai dengan pendapat tersebut Chambers (2008: 9) menjelaskan bahwa matematika adalah studi tentang pola, hubungan, dan kaya akan ide-ide yang saling terhubung, serta alat yang digunakan untuk menyelesaikan masalah dalam konteks yang luas. Selain itu, dengan pengamatan terhadap contoh-contoh dan bukan contoh diharapkan peserta didik mampu menangkap pengertian suatu konsep (Suherman, et al, 2003: 57).

Hasil dari analisis tugas yaitu menggunakan cerita dalam kehidupan seharihari dalam membuat soal. Sesuai dengan pendapat Jonassen (2011: 365) bahwa dengan menggunakan masalah cerita, peserta didik didorong untuk memahami sifat dari masalah, memilih formula yang tepat untuk memecahkan masalah, memasukkan nilainilai dari masalah ke dalam rumus, dan untuk memecahkan rumus untuk nilai tertentu. Siswa diberikan soal cerita kemudian diarahkan untuk memecahkan masalah dengan tahap pemecahan masalah. Hal tersebut sesuai dengan yang disampaikan Lee (2006: 52) bahwa matematika adalah proses pencarian pola secara sistematis yang dapat digunakan untuk memodelkan dunia secara singkat dan jelas. Hasil analisis tujuan pembelajaran yang dicantumkan dalam bahan ajar elektronik adalah mengarahkan siswa untuk lebih menyukai matematika dan memperkenalkan tahap proses pemecahan masalah agar siswa bisa berpikir kritis. Menurut Haylock (2007: 3) kegiatan pembelajaran matematika bertujuan untuk meningkatkan kemampuan siswa dalam berpikir logis, keterampilan memecahkan masalah, serta kemampuan berpikir abstrak. Setelah melakukan tahap pendefinisian, peneliti melakukan tahap perancangan.

\section{Hasil Uji Coba Produk}

Uji coba produk bertujuan untuk menyempurnakan Bahan Ajar Elektronik (BAE) berbantuan flipbook yang dikembangkan. Tahap uji coba yang dilaksanakan meliputi: validasi bahan ajar 
elektronik, uji coba terbatas, dan uji coba lapangan.

\section{Analisis Hasil Validasi Bahan Ajar Elektronik (BAE) Berbantuan flipbook}

Kegiatan validasi dilakukan dengan cara menyerahkan produk awal beserta komponen pendukungnya kepada ahli untuk diberikan skor berkaitan dengan kevalidan hasil pengembangan berupa Bahan Ajar Elektronik
(BAE) berbantuan flipbook. Secara umum hasil penilaian dari tiga validator ahli menyatakan bahwa instrumen sudah layak dan siap dipergunakan untuk penelitian. Skor hasil validasi bahan ajar elektronik diperoleh dengan menggunakan lembar validasi yaitu: lembar validasi Bahan Ajar Elektronik (BAE) berbantuan flipbook. Secara ringkas disajikan pada tabel berikut.

Tabel 6. Skor Hasil Validasi Ahli terhadap Bahan Ajar Elektronik (BAE) berbantuan flipbook

\begin{tabular}{lcccc}
\hline \multirow{2}{*}{ Validator } & \multicolumn{4}{c}{ Skor pada masing-masing aspek } \\
& Isi & Bahasa & Tampilan & Kegunaan \\
\hline Validator 1 & 35 & 8 & 18 & 8 \\
Validator 2 & 37 & 7 & 18 & 6 \\
Validator 3 & 36 & 8 & 17 & 8 \\
Rata-rata Skor & 36 & 7,7 & 17,7 & 7,3 \\
Kriteria & Sangat & Baik & Sangat Baik & Baik \\
& Baik & & & \\
& & & &
\end{tabular}

Berdasarkan kriteria penilaian yang telah dijelaskan, diperoleh hasil validasi ahli. Ratarata skor aktual aspek isi untuk Bahan Ajar Elektronik (BAE) berbantuan flipbook adalah 36 (Sangat Baik) dengan rentang skor 8-40. Rata-rata skor aktual untuk aspek bahasa adalah 7,7 (Baik) dengan rentang skor 2-10. Rata-rata skor aktual untuk aspek tampilan adalah 17,7 (Sangat Baik) dengan rentang skor 4 - 20. Rata-rata skor aktual untuk aspek kegunaan adalah 7,3 (Baik) dengan rentang skor $2-10$. Selain memberikan penilaian terhadap produk yang berupa draf 1 , validator juga memberikan masukan dan saran perbaikan terhadap produk Bahan Ajar Elektronik (BAE).

Beberapa saran yang diberikan dari validator yaitu untuk memperbaiki bahasa agar lebih mudah dipahami oleh siswa, lebih menata tampilan (layout) agar lebih rapi, ukuran file yang digunakan dalam bahan ajar elektronik sebaiknya tidak terlalu besar, desain warna hendaknya lebih bervariasi. Peneliti kemudian melakukan revisi produk berdasarkan saran dari para validator. Berdasarkan hasil validasi, produk Bahan Ajar Elektronik sudah memenuhi kriteria valid, berdasarkan 4 aspek yaitu isi, bahasa, tampilan, dan kegunaan sudah memenuhi kriteria minimal baik. Hasil tersebut didukung oleh pendapat Siddiq dkk (2008: 2-4) bahwa Bahan Pembelajaran Sekolah dasar merupakan seperangkat bahan yang memuat materi atau isi pembelajaran Sekolah Dasar (sesuai kurikulum SD) yang "didesain" dalam bentuk bahan yang digunakan siswa dan guru dalam proses pembelajaran untuk mencapai tujuan pembelajaran di Sekolah Dasar.

\section{Analisis Hasil Uji Coba Terbatas}

Pelaksanaan uji coba terbatas dilaksanakan pada bulan Juli 2017. Pada uji coba terbatas diperoleh data mengenai respon 
siswa dan respon guru terhadap Bahan Ajar Elektronik (BAE) berbantuan flipbook.

\section{Hasil penilaian kepraktisan siswa}

Skor hasil uji coba terbatas untuk penilaian Bahan Ajar Elektronik (BAE) berbantuan flipbook diperoleh dari siswa dengan kemampuan biasa, sedang, dan tinggi.

Tabel 7. Skor Hasil Penilaian Bahan Ajar Elektronik (BAE) berbantuan flipbook oleh Siswa pada Uji Coba Terbatas

\begin{tabular}{|c|c|c|c|}
\hline \multirow{2}{*}{ Pernyataan } & \multicolumn{3}{|c|}{ Total Skor Tiap Tingkatan } \\
\hline & Biasa & Sedang & Tinggi \\
\hline Jenis tulisan dan ukuran huruf dalam BAE mudah saya baca & 28 & 30 & 30 \\
\hline $\begin{array}{l}\text { Gambar yang digunakan dalam BAE memudahkan saya dalam } \\
\text { memahami materi }\end{array}$ & 24 & 26 & 25 \\
\hline BAE menggunakan gambar dan ilustrasi yang menarik & 26 & 24 & 26 \\
\hline Bahasa dalam BAE mudah saya pahami & 26 & 27 & 26 \\
\hline Tampilan LKS menarik & 26 & 22 & 21 \\
\hline $\begin{array}{l}\text { Penjelasan langkah-langkah kegiatan dalam BAE mudah untuk } \\
\text { saya pahami }\end{array}$ & 25 & 26 & 25 \\
\hline Materi yang disajikan dalam BAE mudah saya pahami & 26 & 25 & 25 \\
\hline $\begin{array}{l}\text { BAE ini mendorong keingintahuan saya untuk mencari } \\
\text { informasi lebih jauh tentang materi yang diajarkan }\end{array}$ & 25 & 27 & 24 \\
\hline $\begin{array}{l}\text { BAE ini menjelaskan suatu materi menggunakan ilustrasi } \\
\text { dalam kehidupan sehari-hari }\end{array}$ & 25 & 23 & 25 \\
\hline Saya senang dengan materi dalam BAE yang diajarkan di kelas & 25 & 27 & 26 \\
\hline $\begin{array}{l}\text { Materi yang ada dalam BAE menjadikan saya semangat untuk } \\
\text { belajar }\end{array}$ & 24 & 25 & 25 \\
\hline $\begin{array}{l}\text { Saya menginginkan agar guru menggunakan Bahan Ajar } \\
\text { Elektronik (BAE) }\end{array}$ & 22 & 25 & 24 \\
\hline $\begin{array}{l}\text { Saya bersemangat untuk berdiskusi dengan teman satu } \\
\text { kelompok }\end{array}$ & 24 & 24 & 24 \\
\hline $\begin{array}{l}\text { Saya merasa lebih mudah memahami materi pelajaran dengan } \\
\text { menggunakan BAE }\end{array}$ & 21 & 21 & 24 \\
\hline $\begin{array}{l}\text { Saya merasa lebih semangat untuk berbagi pengetahuan dengan } \\
\text { teman }\end{array}$ & 26 & 25 & 25 \\
\hline Jumlah skor tiap tingkatan & 373 & 377 & 375 \\
\hline Rata-rata skor tiap tingkatan & 62,2 & 62,8 & 62,5 \\
\hline Skor total & & 1125 & \\
\hline Rata-rata skor total & & 62,5 & \\
\hline Kategori & & Baik & \\
\hline
\end{tabular}

Uji coba terbatas bertujuan untuk kemampuan tinggi yaitu 62,5 (Baik). Ratamengetahui kepraktisan Bahan Ajar rata skor total untuk penilaian Bahan Ajar Elektronik (BAE) berbantuan flipbook. Elektronik (BAE) berbantuan flipbook pada Rentang rata-rata skor untuk penilaian Bahan uji coba terbatas yaitu 62,5 (Baik). Ajar Elektronik (BAE) berbantuan flipbook Berdasarkan hasil analisis tersebut, dapat oleh siswa pada masing-masing tingkat diketahui bahwa siswa antusias dalam kemampuan yaitu 15 - 75. Rata-rata skor mengikuti kegiatan pembelajaran dan siswa untuk penilaian Bahan Ajar Elektronik (BAE) tertarik mengunakan Bahan Ajar Elektronik berbantuan flipbook oleh siswa dengan (BAE) yang dikembangkan.

kemampuan biasa yaitu 62,2 (Baik); rata-rata skor siswa dengan kemampuan sedang yaitu 62,8 (Baik) ; dan rata-rata skor siswa dengan 


\section{Hasil penilaian kepraktisan guru}

Skor uji coba terbatas untuk perangkat pembelajaran diperoleh dari dua orang guru matematika yang mengajar di Kelas V SD Negeri 17 Kuningan sebagai berikut.

Tabel 8. Skor Kepraktisan Uji Coba Terbatas dari Guru

\begin{tabular}{lccc}
\hline Guru Mata Pelajaran & Materi & $\begin{array}{c}\text { Aspek BAE } \\
\text { Bahasa }\end{array}$ & $\begin{array}{c}\text { Ketertarikan } \\
\text { dan Pengaruh }\end{array}$ \\
\hline Guru 1 & 26 & 14 & 34 \\
Guru 2 & 25 & 13 & 36 \\
Rata-rata & 25,5 & 13,5 & 35 \\
Kriteria & Sangat Baik & Sangat Baik & Sangat Baik \\
\hline
\end{tabular}

Pengambilan data dilakukan sebelum pelaksanaan uji coba lapangan, hal ini dilakukan agar diperoleh gambaran awal perangkat pembelajaran yang dikembangkan sehingga memperoleh masukan dari guru untuk bahan revisi. Rata-rata skor aktual untuk materi adalah 25,5 (Sangat Baik) dengan rentang skor 6 - 30. Rata-rata skor untuk Bahasa adalah 13,5 (Sangat Baik) dengan rentang skor $3-15$. Rata-rata skor untuk ketertarikan dan pengaruh adalah 35 (Sangat Baik) dengan rentang skor 8-40. Berdasarkan hasil analisis tersebut, dapat diketahui bahwa guru tertarik mengunakan Bahan Ajar Elektronik yang dikembangkan.

\section{Analisis Hasil Uji Coba Lapangan}

Analisis Hasil Tes Kemampuan Pemecahan Masalah. Skor diperoleh dengan menggunakan instrumen tes kemampuan pemecahan masalah yang telah dirancang dan divalidasi.

Kemampuan memahami masalah siswa naik 4 poin, kemampuan menyusun rencana naik 114 poin, kemampuan melaksanakan rencana 181 poin, kemampuan melihat kembali naik 130 poin.

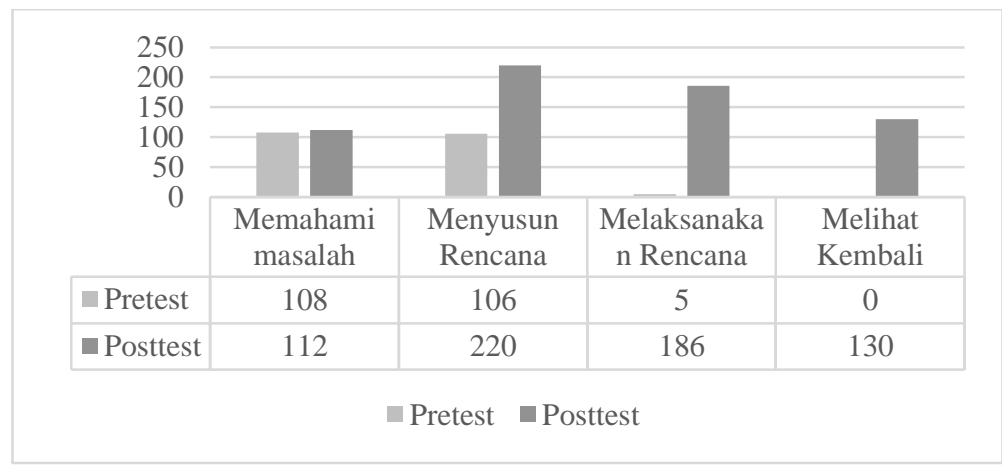

Gambar 1. Hasil Analisis Kemampuan Pemecahan Masalah

Pada posttest pertama nilai kemampuan pemecahan masalah Kelas VB rentang nilai yang dicapai siswa adalah nilai terendah 67,9 dan tertinggi 92,9. Ketuntasan hasil tes kemampuan pemecahan masalah siswa pada posttest mencapai $92,9 \%$. Berdasarkan data tersebut dapat diketahui bahwa Bahan Ajar Elektronik dapat meningkatkan kemampuan siswa dalam memecahkan masalah. Schroeder \& Lester (NCTM, 2000: 182) 
menyatakan bahwa pemecahan masalah merupakan sarana mempelajari ide matematika dan keterampilan matematika. Sesuai dengan hal tersebut Pimta (2009: 381) menyatakan bahwa masalah matematika adalah alat yang digunakan untuk membantu siswa mengembangkan kemampuan berpikir mereka.

\section{Analisis Hasil Angket Sikap terhadap}

\section{Matematika}

Skor diperoleh dengan menggunakan instrumen angket sikap terhadap matematika yang telah dirancang dan divalidasi. Reliabilitas instrumen angket sikap diperoleh dengan melakukan uji coba angket di Kelas VA. Berdasarkan hasil yang didapat, koefisien alpha untuk angket sikap terhadap matematika sebesar 0,92 .

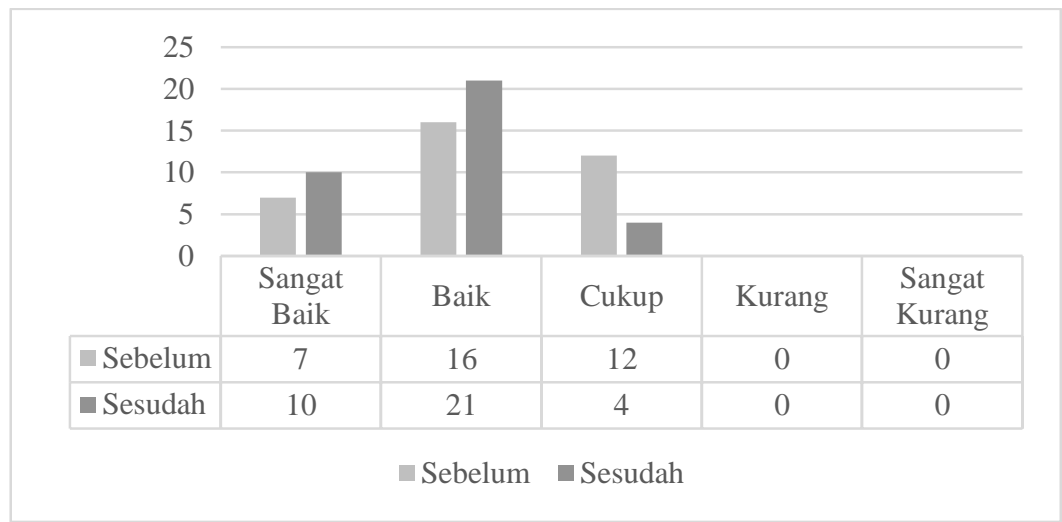

Gambar 2. Hasil Analisis Sikap Siswa terhadap Matematika

Data hasil angket sikap terhadap matematika diambil sebelum dan sesudah pembelajaran pada tahap uji coba lapangan. Persentase siswa dengan kategori sangat baik meningkat $42,8 \%$, persentase siswa dengan kategori baik meningkat $31,25 \%$. Berdasarkan data tersebut dapat diketahui bahwa Bahan Ajar Elektronik dapat meningkatkan sikap positif siswa terhadap matematika. Menurut Kunandar (2014: 103) sikap bermula dari dari perasaan (suka atau tidak suka) yang terkait dengan kecenderungan seseorang dalam merespon sesuatu atau objek. Agar siswa aktif dalam pembelajaran matematika maka diperlukan sikap positif terhadap matematika. Leder (1992: 1) mengemukakan bahwa tujuan penting dari pendidikan matematika adalah untuk mengembangkan sikap positif siswa terhadap matematika. Hal tersebut sesuai dengan pendapat Manoah, Indoshi, \& Othuon
(2011: 965) bahwa sebaiknya sikap siswa ditingkatkan dalam pembelajaran matematika karena hal ini dapat meningkatkan prestasi akademik. Selain itu, menurut Mohamed \& Waheed (2011: 277) sikap terhadap matematika merupakan faktor yang mempengaruhi prestasi belajar matematika.

\section{SIMPULAN}

Bahan Ajar Elektronik (BAE) berbantuan flipbook berbasis keterampilan pemecahan masalah dengan pendekatan CTL pada pembelajaran matematika Kelas V Sekolah Dasar yang diujicobakan di SD Negeri 17 Kuningan dikategorikan valid. Bahan Ajar Elektronik (BAE) berbantuan Flipbook masuk kategori valid. Rata-rata skor aktual aspek isi untuk Bahan Ajar Elektronik (BAE) berbantuan flipbook adalah 36 (Sangat Baik) dengan rentang skor 8 - 40. Rata-rata skor 
aktual untuk aspek bahasa adalah 7,7 (Baik) dengan rentang skor 2 - 10. Rata-rata skor aktual untuk aspek tampilan adalah 17,7 (Sangat Baik) dengan rentang skor $4-20$. Rata-rata skor aktual untuk aspek kegunaan adalah 7,3 (Baik) dengan rentang skor 2-10. Berdasarkan hasil tersebut maka Bahan Ajar Elektronik (BAE) berbantuan flipbook berbasis keterampilan pemecahan masalah dengan pendekatan CTL pada pembelajaran matematika Kelas V Sekolah Dasar layak digunakan sebagai sumber belajar. Hasil uji coba menunjukkan bahwa Bahan Ajar Elektronik yang dikembangkan praktis dan efektif. Kepraktisan BAE yang dinilai oleh siswa mencapai 62,5 dengan kategori baik dan kepraktisan BAE yang dinilai oleh guru mencapai 25,5 (sangat baik) pada aspek materi; 13,5 (sangat baik) pada aspek bahasa; serta 35 (sangat baik) pada aspek ketertarikan dan pengaruh. Ketuntasan hasil tes kemampuan pemecahan masalah siswa pada posttest mencapai 92,9\%. Terjadi peningkatan skor yang diperoleh siswa pada tahap memahami masalah, menyusun rencana, melaksanakan rencana, dan melihat kembali. Persentase sikap siswa terhadap matematika dengan kategori sangat baik meningkat $42,8 \%$, persentase sikap siswa terhadap matematika dengan kategori baik meningkat $31,25 \%$.

\section{DAFTAR PUSTAKA}

Anwariningsih, Huning Sri. (2014). Kesiapan Penggunaan ICT pada Sekolah Dasar di Daerah Rural dalam Perubahan Paradigma Pembelajaran. Seminar Nasional dan Call For Papers UNIBA.

Chambers, P. (2008). Teaching mathematics: developing as a reflective secondary teacher. London: SAGE Publications.

Guan, Eng Tay, et al. (2011). Assessment in the mathematics classroom (affective assessment in the mathematics classroom: a quick start). Singapore: World Scientific Publishing.

Haylock, D. \& Tangatha, F. (2007). Key concepts in teaching primary mathematics. London: Sage Publications.

Hobri, H. (2010). Metodologi penelitian pengembangan (aplikasi pada penelitian pendidikan matematika). Jember: Pena Salsabila.

Hosnan, M. (2014). Pendekatan saintifik dan kontekstual dalam pembelajaran abad 21 kunci sukses implementasi Kurikulum 2013. Bogor: Ghalia Indonesia.

Jonassen, D. H. (2011). Learning to solve problems, a handbook for designing problem-solving learning environments. New York: Routledge.

Kunandar. (2014). Penilaian autentik (penilaian hasil belajar peserta didik berdasarkan Kurikulum 2013) suatu pendekatan praktis. Jakarta: Rajagrafindo Persada. 
Leder, G. (1992). Attitude to mathematics. Mathematics Education Research Journal, Vol 4, No. 3, 1-7.

Lee, C. (2006). Language for learning mathematics: assessment for learning in practice. New York: Open University Press.

Mendikbud. (2014). Lampiran I Peraturan Menteri Pendidikan dan Kebudayaan Nomor 58, Tahun 2014, tentang Kurikulum 2013 Sekolah Menengah Pertama/Madrasah Tsanawiyah.

Manoah, S.A., Indoshi, F.C., \& Othuon, L.O.A. (2011) Influence of attitude on performance of students in mathematics curriculum. Educational Research, 2(3), 965-981.

Mayer. (2009). Mutimedia learning, prinsip-prinsip dan aplikasi. Yogyakarta: Pustaka Pelajar.

Mohamed, L. \& Waheed, H. (2011). Secondary students' attitude towards mathematics in a selected school of Maldives. International Journal of Humanities and Social Science, 1, 277-281.

Munir. (2013). Multimedia Konsep dan Aplikasi dalam Pendidikan. Bandung: Alfabeta.

NCTM. (2000). Principles and standars for school mathematics. Reston: The National Council of Teacher of Mathematics, Inc.

Nieveen, N. (1999). Prototyping to reach product quality. Dalam J. Van Den Akker, et al (Eds.), Design approaches and tools in education and training. London, UK: Kluwer Academic Publisaher.

Pimta, S; Tayruakham, S., \& Nuangchalerm, P. (2009). Factors influencing mathematics problem-solving ability of sixth grade students. Journal of social sciences, 5(4), 381-385.

Peraturan Pemerintah Republik Indonesia Nomor 19, Tahun 2005, tentang Standar Nasional Pendidikan.

Suherman, E., et al. (2001). Strategi pembelajaran matematika kontemporer. Bandung: JICA.

Surjono, Herman Dwi. (2010). Pemanfaatan teknologi informasi dan komunikasi dalam peningkatan kualitas pembelajaran. Makalah. Disajikan dalam seminar MGMP Terpadu SMP/MTs Kota Magelang.

Siddiq, Djauhar M; Isniatun Munawaroh; Sungkono. (2008). Pengembangan bahan pembelajaran SD. Jakarta: Dikti.

Thiagarajan, et al. (1974). Instructional development for training teachers of exceptional children: a sourcebook. Bloomington: Indiana University.

Widoyoko, E, P. (2009). Evaluasi program pembelajaran panduan praktis bagi pendidik dan calon pendidik. Yogyakarta: Pustaka Pelajar. 